\title{
CONFRONT ISSUES ON EDUCATION OF TRANSGENDERS IN INDIA
}

\author{
Dr. A. Balu
}

\author{
Principal, Alagappa University College Of Education, Alagappa University, \\ Karaikudi, Tamilnadu
}

ABSTRACT The spirit of the Indian Constitution is to provide equal opportunity to every citizen to grow and attain their potential, irrespective of caste, religion or gender. Everyone has a gender identity. In India there are three gender; male, female and transgender. The Transgender community is a part of the social order and they have an equal right in everything that is available to all others in the world. The presence of such transgender is not new and is etched in history from time immemorial. Transgenders were respected earlier in the society but situation has changed and they now face discrimination and harassment. Now, transgenders will study in schools and colleges with all facility approving their admission under the category of "disadvantaged group" defined by the Right to Education Act2009 (RTE). Transgenders are eligible for twenty five percent reservation under the economically weaker section (EWS) and disadvantaged students category for admission.Many members of the transgender community were torch bearers of changes in the events of history even if they aren't specifically noted. Their discrimination has been a perennial issue and has only proven to be more spurious with time. The discrimination the members of the transgender community face based on their class and gender make them one of the most disempowered groups in Indian Society. The Supreme Court said they will be given educational and employment reservation as OBCs.Transgenders are deprived of social and cultural participation, are shunned by family and society.The paper has analysed the present educational, social and employment status of transgender community in India.

KEYWORDS : Discrimination, Transgender, Disadvantage Group And Confidentiality

\section{INTRODUCTION}

The term 'transgender' refers to signify individuals who go beyond rigid, binary gender constructions. Such resistance is facilitated through the breaking and blurring of culturally prevalent stereotypical gender roles. Third Genders are mostly castrated males who have a long history that dates back to 9th Century B.C. These newly castrated men were normally employed in imperial quarters for women as guards. The right to choose one's gender identity is an essential part to lead a life with dignity which again falls under the ambit of Article 21. Determining the right to personal freedom and selfdetermination, the Court observed that "the gender to which a person belongs is to be determined by the person concerned." The Court has given the people of India the right to gender identity. The term transgender encompasses a wide range of identities, appearances, and behaviors that blur or cross gender lines. Within this transgender umbrella are transse xuals, who live some or all of the time in a sex different from their biological sex; cross-dressers (formerly called transvestites), who wear clothes typically associated with the "opposite" gender; drag kings and drag queens, who crossdress within a performance context; and gender queers, who identify outside of binary gender or sex systems. This paper discusses the experiences of transgender students and how student affairs professionals may effectively address these students' needs in areas of campus life where transgender students have unique concerns: programming, housing, bathrooms and locker rooms, counseling and health care, and records and documents. As this area demonstrates, transgender students regularly encounter institutional discrimination in higher education, which makes it particularly important that student affairs professionals understand their experiences and the obstacles they confront at most colleges and universities.

\section{STATUS OF TRANSGENDER EDUCATION}

Third Gender i.e. Transgender is a new sex in Indian Constitution. This new sex emerges with a major population. They are deprived of social and cultural participation and hence they have restricted access to education, health care and public places which further deprives them of the Constitutional guarantee of equality before law and equal protection of laws.

\section{EDUCATIONAL STATUS:}

No formal education for transgender is popular in Indian context. They are deprived from family and school enviro nment, transgender discontinue their education and risk their future career opportunities. A close analysis of various reports and discussion with community and stakeholders suggest that transgender are most uneducated or undereducated, become reluctant to continue schooling. The average qualification is secondary (Matric) or senior secondary level. The enrolment is significantly low and dropout rate at the primary and secondary level is still very high. They are hardly educated as they are nor accepted by the society and therefore do not receive proper schooling. Even if they are enrolled in an educational institute, they face harassment and are bullied every day and are asked to leave the school or they drop out on their own. It is because of this that they take up begging and sex work. it mandatory for the Government to provide inclusive education for transgender students and provide adult education to them.

\section{SOCIAL STATUS:}

The transgender community faces stigma and discrimination and therefore has fewer opportunities as compared to others. They are hardly educated as they are nor accepted by the society and therefore do not receive proper schooling. Even if they are enrolled in an educational institute, they face harassment and are bullied every day and are asked to leave the school or they drop out on their own. It is because of this that they take up begging and sex work. They are forced into sex work which puts them at the highest risk of contracting HIV as they agree to unprotected sexual intercourse because they fear rejection or they want to affirm their gender through sex.

\section{PROBLEMS REALTED TO SOCIETAL ACCEPTANCE}

Transgender people often face denial and aggression right from home. The problems range from verbal and physical abuse to isolation and rejection and denial of family property. Sexuality or gender identity often makes transgender a victim of stigmatization and exclusion by the society. Social stigma includes being disempowered due to the labelling and negative/generalised attitude towards such members who are forced to work as sex workers or sex solicitors.

\section{RESIDENCE HALLS:}

Transgender students who live in residence halls, especially single-sex dormitories, can face housing and roommate issues, as well as bathroom problems. Many colleges address 
such situations on a case-by-case basis, but the intent is to accommodate the transgender student. In many instances, a school will offer the student a single room on a mixed-gender floor and, where possible, access to a private bathroom.

\section{TRANSGENDERISM IN ACADEMIA:}

Faculty who transition on the job have to be concerned about how their students will react and whether their transsexuality will affect hiring and tenure decisions. Significantly, however, transgender studies is increasingly being recognized as an important area of academic scholarship.

\section{BATHROOMS:}

Many of the issues faced by transpeople in higher education, including safety concerns, bathroom and health care access, and the proper gender designation on records, also confront transgender students and staff in secondary educati on. Another area where transgender people exper ience discrimination is in their use of public restrooms. The "bathroom issue" is particularly a problem for transsexual women, but butch lesbians and other masculineappearing women are also often harassed in women's restrooms. While non-transgender women should be able to feel safe in this most private of public environments, so too should transsexual and other gender variant women, who have a right to use the restroom appropriate for their gender. College officials who have mediated a restroom conflict have sought to balance the desires of both the transgender individual and the complainant, while recognizing that a transperson should never be denied access to adequate bathroom facilities simply because of someone's bias.

\section{GENDER DESIGNATION ON COLLEGE RECORDS:}

One area where transgender people experience discrimi nation in education is on school documents. Recognizing that college registration and personnel forms that ask students, staff, and faculty to indicate whether they are female or male ignore the complexities of gender and signal that gender variant people do not belong at the institution, transgender advocates are beginning to lobby school administrators to use more inclusive language.

\section{PROBLEMS ASSOCIATED WITH ILLITERACY ZERO ACCEPTANCE LEVEL:}

Transgender community faces high level of stigma and discrimination in almost every walk of their life. Transgender, especially in their growing up years face physical, sexual, emotional violence, violence in terms of neglect and discrimination as well. They often experience isolation and abuses, and are not allowed to share common grounds with classmates. Families and schools prove to be torture chambers for effeminate boys as they face accusations from teachers for violating school and societal decorum.

\section{FORCED ILLITERACY:}

Deprived by both family and school, transgender quit education and thereby limit career opportunities. Reports and discussions with community and stakeholders point to this deprivation as the main cause of rising drop-out rates among transgender community. The average qualification of a transgender is Secondary (Matriculation) or senior secondary level. The enrolment is significantly low and dropout rate at the primary and secondary level is still very high. Bridging the gap of gender disparity and social exclusion remains a huge challenge for the community

\section{LACK OF EMPATHY AND NEED FOR COUNSEL:}

Lead by prevalent societal norms and stigmas, teachers accuse transgender persons. This insensitiveness of teachers towards transgender community has an adverse impact on them. Most of the members of teaching fraternity display lack of knowledge and sensitivity towards the issues of trans gender and hesitant to work for ensuring education. The transgender person who is already excluded from the family and society do not get enough support with the teachers and therefore forced to discontinue the education abruptly.

\section{CHALLENGES OF TRANSGENDER EDUCATION}

The nomenclature "third gender" is a problem in itself: it treats sexuality as a ladder-like structure in which the lowest rung is occupied by the queer community. Although it provides them with legal recognition, it does not alleviate them of their adject conditions as they continue to be a part of the marginalized section of society and are not considered equal to the rest of the Indian population. India has finally been able to successfully adopt the inclusion principle which was for a long time hoped for but not acted upon, it is also important to bring to attention the various ways in which it has been a failure.

\section{USE OF DISRESPECTFUL NAMES AND PRONOUNS:}

To persevere intentionally in the use of a prior name and other pronouns is to be deliberately disrespectful. Transgender youth can understand and sympathize with some confusion, so long as there is continuous, good faith progress in using the proper name and pronouns.

\section{INCLUSION IN SCHOOL/ COLLEGE AND UNIVERSITY:}

Inclusion of transgender with school and college is a big challenge. It is so challenging to provide equal opportunity of education to transgender because there is a problem of inclusion with male and female gender students.

\section{LACK OF IDEAL PERSONALITY:}

Transgender youth often feel alone in the world. Few programs for youth employ transgender people; few libraries offer information about biological sex and gender, gender identity, or being transgender.

\section{CONFIDENTIALITY:}

Transgender youth may have unsupportive families and may even face violence and/or ejection from their home if their gender identity or gender expression is disclosed to the family.

\section{LACK OF ACCESS TO APPROPRIATE RESTROOM FACII} ITIES:

Transgender people often have no safe access to locker room facilities that conform to their gender identity.Wherever dress codes are enforced, they may create problems for transgender youth.

There is need for a focused institutionalized mechanism of research and academic activities to generate more data/information to identify and understand the problems related to various aspects of their life and help frame policies through research and academic program that would bring an effective and long-term change in their lives.

\section{CONCLUSION}

Transgender people faced discrimination and harassmentat family, school and community forces them to move to the other places. The nature of the harassment includes verbal, physical and sexual abuse which has serious impact on the mental health as well. In a democratic country like India Transgender has no access to the social and political rights. They are not the part of any welfare scheme. If institutions are to be welcoming to people of all genders, issues of discrimination and equal access to facilities and health care need to be addressed.

\section{REFERENCES}

1. Stryker, Susan., Transgender History. United States of America: Seal Press. 2008. Print

2.. Rajesh and MD AslamNaved (2013). Approach Paper on Education and Employment opportunities \& Challenges for Transgender.Ministry of Social Justice and Empowerment Government of India retrieved from www.socia lju 
stice.nic.in/pdf/appendix5

3. Bolich.G.G.PhD.Transgender History And Geography Crossdressing In Context,Vol.3. North Carolina: Psyche's Press. 2010. Print

4. Satashivam. P (2012). Rights of Transgender People: Sensitising Officers to Provide Access to Justice.http://www.hcmadra s.tn.nic.in/jacademy/ Article /P SJ-CJO-SPEECH-Royappetah.pdfWikipedia, The free encyclopaedia retri eved from http://en.m.wikipedia.org/wiki/transgender

5. Transgender Law and Policy Institute. "Ways that Colleges and Universities Meet the Needs of Transgender Students." http://www.tra nsgende rlaw.o rg /college/index.htm. Accessed Mar. 15, 2005.

6. Transgender Law and Policy Institute. "College and University Policies." www.transgenderlaw.org/college. 